\title{
Hydroxyapatite Nanopowder Synthesis with a Programmed Resorption Rate
}

\author{
Dariusz Smoleń, ${ }^{1}$ Tadeusz Chudoba, ${ }^{1}$ Stanisław Gierlotka, ${ }^{1}$ \\ Aleksandra Kedzierska, ${ }^{1}$ Witold Lojkowski, ${ }^{1}$ Kamil Sobczak, ${ }^{2}$ \\ Wojciech Święszkowski, ${ }^{3}$ and Krzysztof Jan Kurzydłowski ${ }^{3}$ \\ ${ }^{1}$ Institute of high Pressure Physics, Polish Academy of Science, Sokolowska 29/37, 01-142 Warsaw, Poland \\ ${ }^{2}$ Institute of Physics, Polish Academy of Science, Al. Lotnikow 32/46, 02-668 Warsaw, Poland \\ ${ }^{3}$ Faculty of Materials Science and Engineering, Warsaw University of Technology, Woloska 141, 02-507 Warsaw, Poland
}

Correspondence should be addressed to Dariusz Smoleń, smolendarek@gmail.com

Received 11 September 2012; Revised 18 October 2012; Accepted 1 November 2012

Academic Editor: Yan-Yan Song

Copyright ( 2012 Dariusz Smoleń et al. This is an open access article distributed under the Creative Commons Attribution License, which permits unrestricted use, distribution, and reproduction in any medium, provided the original work is properly cited.

\begin{abstract}
A microwave, solvothermal synthesis of hydroxyapatite (HAp) nanopowder with a programmed material resorption rate was developed. The aqueous reaction solution was heated by a microwave radiation field with high energy density. The measurements included powder X-ray diffraction (PXRD) and the density, specific surface area (SSA), and chemical composition as specified by the inductively coupled plasma optical emission spectrometry technique (ICP-OES). The morphology and structure were investigated using scanning electron microscopy (SEM) and transmission electron microscopy (TEM). A degradation test in accordance with norm ISO 10993-4 was conducted. The developed method enables control of the average grain size and chemical composition of the obtained HAp nanoparticles by regulating the microwave radiation time. As a consequence, it allows programming of the material degradation rate and makes possible an adjustment of the material activity in a human body to meet individual resorption rate needs. The authors synthesized a pure, fully crystalline hexagonal hydroxyapatite nanopowder with a specific surface area from 60 to almost $240 \mathrm{~m}^{2} / \mathrm{g}$, a Ca/P molar ratio in the range of 1.57-1.67, and an average grain size from $6 \mathrm{~nm}$ to over $30 \mathrm{~nm}$. A 28 -day degradation test indicated that the material solubility ranged from 4 to $20 \mathrm{mg} / \mathrm{dm}^{3}$.
\end{abstract}

\section{Introduction}

The number of cases of bone defects requiring replacement has increased rapidly in recent years $[1,2]$. Nevertheless, there is no solution presently available that overcomes the disadvantages and disabilities of current medical practices. Techniques are needed to repair large bone defects and to return patients to their previous quality of life. A primary difficulty is the lack of a proper material which enables the creation of bone scaffolds with the appropriate mechanical strength and a controllable resorption rate. Currently, autografts are the clinical gold standard for bone replacement therapy. Autografts provide the primary factors for effective bone regeneration, but they also impose a significant cost and risk [3-5].
One potential solution marketed as filler for small bone gaps and defects is a bioactive ceramic made of micro- and sub-microhydroxyapatite. Due to their strong similarity to the mineral phase of native bone, called apatite, bioactive ceramics display appropriate levels of osteoconductivity and biocompatibility $[6,7]$. Additionally, the interaction of osteogenic cells with this material leads to good bone bonding and bone regeneration [8]. Although micro- or sub-microhydroxyapatite powder is suitable for recovering small bone gaps, in more complicated cases it has several drawbacks like the lack of possibility to control the material resorption rate $[9,10]$. These disadvantages may be reduced or eliminated by replacing the micropowder by a hydroxyapatite nanopowder. The latter has grains much smaller than $100 \mathrm{~nm}$, possibly giving it unexpected 
properties that are necessary to achieve a proper bioactivity and biodegradability levels. These nanoparticles have a significantly greater surface-to-volume ratio than powders with larger grains; thus, they have increased surface energy $[11,12]$. Consequently, the surface energy-related features such as the solubility may be controlled. According to the Ostwald-Freudlich equation [13], the material solubility increases with increased specific surface area. A decrease in the HAp particle size to a few nanometers should significantly increase the material solubility [13]. The ability to regulate the particle size thus enables the control of the material degradation rate. Additionally, as the literature shows [14], osteoblast adhesion is strongly driven by the material surface area and topography. A decrease in the particle size increases the osteoblast adhesion as it is directly related [14] to the greater surface area.

A second important feature which influences the HAp bioactivity is its stoichiometry. Bone mineral has a $\mathrm{Ca} / \mathrm{P}$ molar ratio near 1.50 , which is close to the tricalcium phosphate (TCP) stoichiometry, but structurally and chemically it is similar to the stoichiometric $\mathrm{HAp}$ with a $\mathrm{Ca} / \mathrm{P}$ molar ratio equal to 1.67 [15]. The ion exchange or degradation rate is strongly dependent on the bioactive ceramic stoichiometry. With calcium deficiency increase, the number of crystalline structure defects caused by calcium ions vacancies increases which is reducing material stability and in consequence increasing its solubility $[15,16]$.

The literature presents various methods for hydroxyapatite nanoparticle synthesis; these include processes conducted by mills $[17,18]$, hydrothermal syntheses conducted in a typical vessel with conventional heating $[19,20]$, solgel methods $[21,22]$, and even synthesis by emulsion [23, 24]. In most cases, the synthesized powder is stoichiometric hydroxyapatite, and in many cases it includes additional phases and substances such as byproducts or unreacted substrates. Usually the powder's degradation rate is too low to adjust to bone scaffolding needs and it is not possible to program its solubility in advance, which is necessary for bone implant development to overcome the previously described barriers. Microwave heating is a potential solution, as it may result in a product that fulfills the previously described requirements. It has been used as a source of energy [25-27], but to our best knowledge, never in a closed system with an energy density equal to or above $5 \mathrm{~W} / \mathrm{mL}$. Microwave radiation is able to evenly and rapidly heat an entire volume of a vessel almost without a temperature gradient in the heated materials $[28,29]$. Additionally, it enables the necessary control of the reaction parameters, so there is the possibility of obtaining a fully crystalline, nonequilibrium structure with a programmed grain-size distribution [30, 31].

The purpose of this work was to develop a microwave solvothermal synthesis method (MSS) based on high energy density microwave radiation [32] which results in pure, nonstoichiometric hydroxyapatite nanoparticles with a programmed particle size, that is, able to regulate the degradation rate of bone scaffolds. The novelty of the presented method lies in its extremely short synthesis time, ranging from 90 seconds to 10 minutes, which is made possible by the implementation of a microwave reactor with a high energy density reaching $5 \mathrm{~W} / \mathrm{mL}$. This paper presents the chemical, physical, and biological properties of the obtained material, including its chemical composition, structure, morphology, and solubility.

\section{Experimental Methods}

2.1. Material Preparation. The hydroxyapatite nanocrystals were obtained by the following method, described in detail in [33]. The starting materials used for the HAp synthesis were calcium hydroxide $\left(\mathrm{Ca}(\mathrm{OH})_{2}, \mathrm{CHEMPUR}\right.$, pure) and phosphoric acid $\left(\mathrm{H}_{3} \mathrm{PO}_{4}, 85 \%\right.$ solution, CHEMPUR, pure for analysis); the reactants were used in a molar ratio $\mathrm{Ca} / \mathrm{P}$ of 1.67. To form a reaction solution, phosphoric acid was added dropwise to the calcium solution at a rate of $0.01 \mathrm{~mL}$ every 3 seconds, and the solution was intensively stirred at room temperature. After 30 minutes of additional stirring, the reaction solution was transferred into a capped Teflon vessel and heated using microwave radiation. The microwave reactor was produced by ERTEC (Wroclaw, Poland) and was operated at $2.45 \mathrm{GHz}$ and at a power density adjusted to approximately $5 \mathrm{~W} / \mathrm{mL}$. The time, temperature, pressure, and microwave power were computer-controlled. The synthesis conditions encompassed pressures ranging from 1 to $32 \mathrm{MPa}$ and times ranging from $1.5 \mathrm{~min}$ to $10 \mathrm{~min}$. After the synthesis, the obtained powder was washed by anhydrous ethanol and dried in an air flow at a temperature of $30^{\circ} \mathrm{C}$ for $16 \mathrm{~h}$. Herein, this resulting material is referred to as "GoHAP" with the addition of the reaction time (e.g., GoHAP $1.5 \mathrm{~min}$ ).

The hydroxyapatite nanopowder NanoXIM201 (FLUIDINOVA, ENGENHARIA DE FLUIDOS, SA TECMAIAParque de Ciência e Tecnologia da Maia Rua Eng ${ }^{\circ}$ Frederico Ulrich, 2650 4470-605 Moreira da Maia, Portugal) was used as a reference material in the degradation test and in the PXRD analysis. To the authors' knowledge, this commercially available hydroxyapatite powder had the lowest available particle size on the market. Its characteristics were a density of $2.93 \mathrm{~g} / \mathrm{dm}^{3}$, an SSA of $120 \mathrm{~m}^{2} / \mathrm{g}$, an average particle diameter calculated from SSA of $17 \mathrm{~nm}$, and a Ca/P molar ratio declared by the producer and confirmed by the authors of 1.66. Figure 1 presents SEM micrograph of NanoXIM201 nanopowder.

Additionally, an XRD analysis using a plate from a pig's shank bone was used as a reference for natural apatite.

2.2. Material Characterization. The density measurements were performed using a helium pycnometer (Micromeritics AccuPyc, model 1330) using an in-house procedure [34]. The specific surface area (SSA) of the powders was measured by the Brunauer-Emmett-Teller (BET) method (Micromeritics AccuPyc, model Gemini 2360). The average diameter of the particles was calculated based on the specific surface area and density, assuming that all of the particles were spherical and identical [34].

The phase composition of the reaction products was analyzed by powder X-ray diffraction (Panalytical X'Pert 


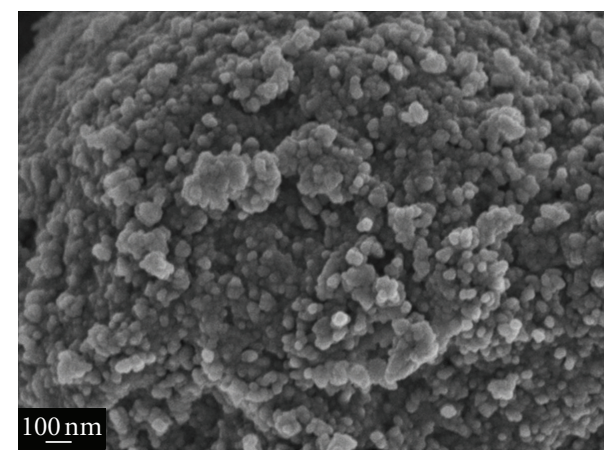

FIGURE 1: SEM micrograph of NanoXIM201 nanopowder produced by the Fluidinova Company.

PRO diffractometer, $\mathrm{Cu}$ Kal radiation). The patterns were collected at room temperature in the 2 theta range $10-150^{\circ}$ and with a step of $0.03^{\circ}$. The pattern analysis was performed by whole pattern fitting (the Rietveld method) using the DDM software suite [35]. The particle size was determined by the Scherrer equation.

The morphology of the nanopowder samples was examined with SEM (ZEISS LEO 1530) and TEM (JEOL JEM2000EX). The TEM investigations, high-resolution TEM (HRTEM), and selected area electron diffraction (SAED) were conducted at $200 \mathrm{kV}$. The specimens for the TEM observations were prepared by dropping the methanol particle dispersion, created by an ultrasonic technique, on a carbon film supported on a 300 mesh copper grid. Additionally, TEM studies were used to determine the nanoparticle size distribution. The grain size histograms were obtained by considering a region of a sample having about 250 nanocrystals and approximating the shape of each nanocrystal by a sphere. The obtained histograms were fitted to either normal or log-normal distributions (Chi-square test and Person's coefficient).

The chemical composition of the powders was determined by inductively coupled plasma optical emission spectrometry (ICP-OES), with induction in argon plasma (Jobin-Yvon, model 138 Ultrace).

The determination of material solubility was performed according to norm ISO 10993-14: biological evaluation of medical devices-identification and quantification of degradation products from ceramics. The material was tested in the form of a $6 \mathrm{~mm}$ disk (each disk was around $35 \mathrm{mg}$ and was created from the nanopowder using a laboratory hydraulic press under $5 \mathrm{MPa}$ pressure) and was placed in $200 \mathrm{~mL}$ of buffer solution (TRIS- $\mathrm{HCl}$ buffer with $\mathrm{pH}$ $7.4 \pm 0.1$ ). A simulation solution test, lasting 28 days, was conducted without buffer solution exchange during the entire test. During the degradation test the samples were incubated at $37.0^{\circ} \mathrm{C}$. Along with the degradation of the samples, the calcium ion concentration value was measured three times per week with an ion selective electrode (Schott ProLab 2000 GLP equipped with ion electrode type CA60). Additionally, the material solubility was determined by the gravimetric method.

\section{Results and Discussion}

With the shortest reaction of 1.5 min of microwave radiation, the obtained GoHAP had a density equal to $2.91 \mathrm{~g} / \mathrm{cm}^{3}$, which is $4 \%$ lesser than the value given in the literature for hydroxyapatite, $3.05 \mathrm{~g} / \mathrm{cm}^{3}$ [36]. It was observed that with nanoparticles, there was a reduction in the material density probably caused by the high contribution of surface layers, which are less densely packed than the bulk [37]. The material's specific surface area was $236 \pm 5 \mathrm{~m}^{2} / \mathrm{g}$, and the average particle diameter calculated based on SSA was $9 \mathrm{~nm}$. Longer microwave radiation slowly increased the material density and significantly decreased the specific surface area (Figure 2); details are presented in Table 1. For the 2.5minute reaction, the specific surface area of GoHAP was reduced by over $60 \mathrm{~m}^{2} / \mathrm{g}$ to $174 \mathrm{~m}^{2} / \mathrm{g}$, and the density increased to $2.94 \mathrm{~g} / \mathrm{cm}^{3}$ comparing to the $1.5 \mathrm{~min}$ reaction. The average particle size calculated based on the specific surface area increased to $12 \mathrm{~nm}$. With 5 minutes of microwave radiation, the SSA decreased to under $100 \mathrm{~m}^{2} / \mathrm{g}$. The density increased by $0.02 \mathrm{~g} / \mathrm{cm}^{3}$ to $2.96 \mathrm{~g} / \mathrm{cm}^{3}$; the average particle size exceeded $20 \mathrm{~nm}$. Within extension of the reaction time over 5 minutes, there was a decrease in the specific surface area to $81 \mathrm{~m}^{2} / \mathrm{g}$ for the 7.5 -minute reaction and $63 \mathrm{~m}^{2} / \mathrm{g}$ for the 10-minute reaction. Consequently, the density became $3.00 \mathrm{~g} / \mathrm{cm}^{3}$ and the particle size became $25 \mathrm{~nm}$ for the 7.5 minute reaction. For the 10 -minute reaction, the resulting particles had an average size of $32 \mathrm{~nm}$ and a density of $3.03 \mathrm{~g} / \mathrm{cm}^{3}$, which was almost equal to the literature values for hydroxyapatite [36].

The ICP-OES analysis indicated that for $1.5 \mathrm{~min}$ reaction, the $\mathrm{Ca} / \mathrm{P}$ molar ratio was equal to 1.57 , which is close to the molar ratios of the natural bone calcium and phosphor elements [36]. Longer microwave heating increased the $\mathrm{Ca} / \mathrm{P}$ molar ratio to values close to stoichiometric HAp (Figure 3); with 2.5 minutes of reaction the $\mathrm{Ca} / \mathrm{P}$ molar ratio changed to 1.65 which is a value frequently indicated in papers presenting HAp synthesis [17-24]. After 5.0 minutes of reaction, the ratio was equal to 1.66 , and further radiation led to fully stoichiometric hydroxyapatite. In all cases the obtained powder included $0.20-0.22 \mathrm{wt} \%$ magnesium ions.

The XRD analysis was conducted on GoHAP powders obtained from 1.5-, 2.5-, 5.0-, and 10.0-minute reactions and using a plate from a pig's shank bone as a reference for natural apatite (Figure 4). The results confirmed that the GoHAP powders were a pure well-crystalline hexagonal hydroxyapatite with nanosized particles. No indication of the presence of other crystalline phases or any amorphous component was found. The lattice parameters for the GoHAP powders are presented in Table 2 , and the pig bone results were $a=9.42(5) \AA$ and $c=6.87(7) \AA$. Other crystal structure parameters could not be derived with satisfying precision due to the considerable anisotropy size and the very small absolute crystal size. However, it was apparent that the crystals obtained in the reaction with 10 minutes of microwave radiation were approximately 10 times larger than the crystals of GoHAP obtained from the 1.5 minute reaction.

The morphology investigation was conducted with SEM and TEM techniques. Figure 5 shows SEM micrographs 


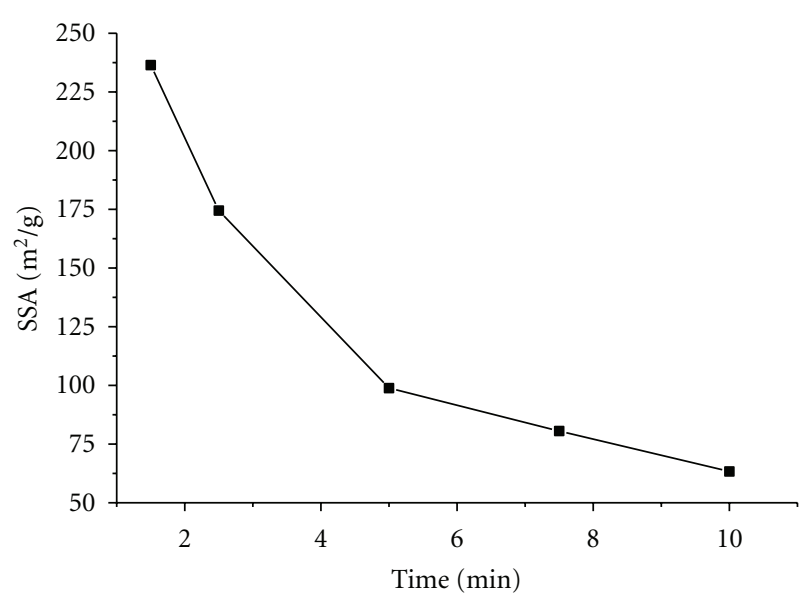

Figure 2: Effect of the microwave radiation time on the specific surface area.

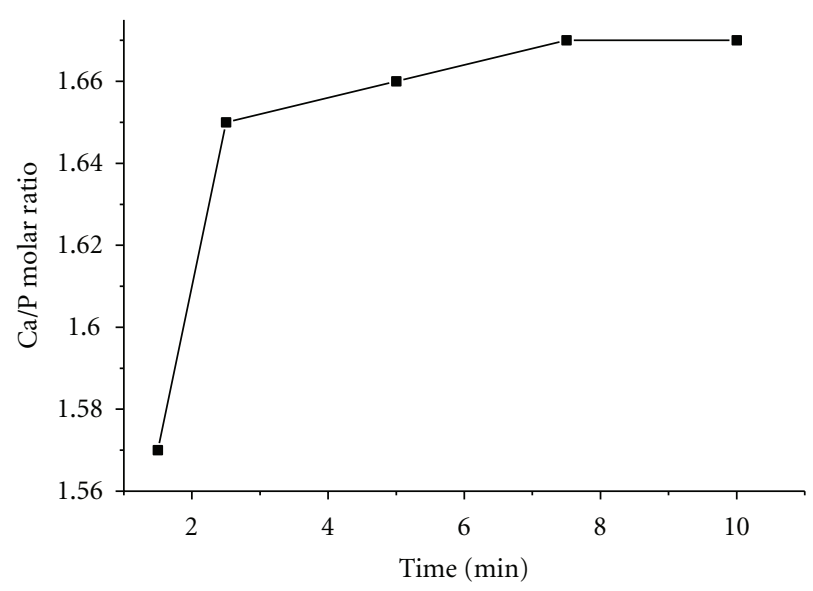

Figure 3: Effect of the microwave radiation time on the Ca/P molar ratio.

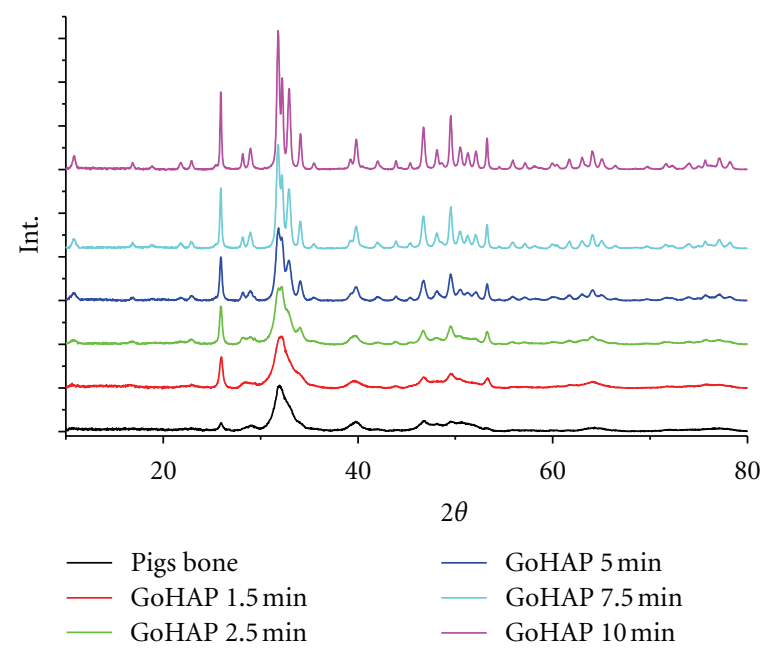

FIGURE 4: XRD patterns of HAp particles in pig bone and GoHAP powders synthesized with microwave radiation times of 1.5, 2.5, 5.0, and 10.0 minutes.
TABLE 1: Effect of the microwave radiation time on the material specific surface area, the density, the grain size calculated on the basis of SSA measurements, and the $\mathrm{Ca} / \mathrm{P}$ ratio established by the ICP-OES measurements.

\begin{tabular}{lcccc}
\hline $\begin{array}{l}\text { Radiation time } \\
(\mathrm{min})\end{array}$ & $\begin{array}{c}\text { SSA } \\
\left(\mathrm{m}^{2} / \mathrm{g}\right)\end{array}$ & $\begin{array}{c}\text { Density } \\
\left(\mathrm{g} / \mathrm{cm}^{3}\right)\end{array}$ & $\begin{array}{c}\text { Grain size } \\
(\mathrm{nm})\end{array}$ & $\mathrm{Ca} / \mathrm{P}$ \\
\hline 1.5 & 236 & 2.91 & 9 & 1.57 \\
2.5 & 174 & 2.94 & 12 & 1.65 \\
5.0 & 99 & 2.96 & 21 & 1.66 \\
7.5 & 81 & 3.00 & 25 & 1.67 \\
10.0 & 63 & 3.03 & 32 & 1.67 \\
\hline
\end{tabular}

TABLE 2: Effect of the microwave radiation time on the lattice parameters determined by the XRD analysis.

\begin{tabular}{lcc}
\hline $\begin{array}{l}\text { Radiation time } \\
(\mathrm{min})\end{array}$ & $\begin{array}{c}\text { Lattice parameter } a \\
( \pm 0.001 \AA)\end{array}$ & $\begin{array}{c}\text { Lattice parameter } c \\
( \pm 0.0007 \AA)\end{array}$ \\
\hline 1.5 & 9.433 & 6.8745 \\
2.5 & 9.439 & 6.8775 \\
5.0 & 9.429 & 6.8772 \\
7.5 & 9.425 & 6.8767 \\
10.0 & 9.423 & 6.8777 \\
\hline
\end{tabular}

of GoHAP nanoparticles for reaction times of $1.5 \mathrm{~min}$, $2.5 \mathrm{~min}, 5.0 \mathrm{~min}$, and $10.0 \mathrm{~min}$. Figure 5 (a) presents the strong homogeneity of GoHAP obtained from the $1.5 \mathrm{~min}$ reaction and confirms that the average particle size of the synthesized hydroxyapatite was less than $10 \mathrm{~nm}$. The powder obtained with 1 minute longer reaction (2.5 minutes) had a larger average particle size as observed on a SEM micrograph (Figure 5(b)). Instead of being homogeneous as with the powder from the shortest reaction time, this powder appeared in the form of agglomerates with diverse sizes. Further microwave heating (5.0- and 7.5-minute reactions) increased the size of both the single particles and their agglomerates. The nanopowder presented in Figure 5(c) was obtained from the 5-minute reaction. Compared to GoHAP synthesized in the shortest reaction, its morphology was highly diverse, and several times the larger particles were grouped in agglomerates with sub-micro- and microsizes. Finally, the reaction with 10 minutes of microwave radiation led to a significant increase in the single particle size and decreased the powder agglomeration degree (Figure 5(d)). The GoHAP powder after the longest reaction time was in form of large, slightly agglomerated particles with an average grain size close to $50 \mathrm{~nm}$.

A TEM examination showed that for all microwave radiation times, the obtained hydroxyapatite had the space group P.P63/m of a hexagonal crystal structure with the parameters $a=9.424(4) \AA$ and $c=6.879(4) \AA$ [38]. An increase in the reaction time did not have any visible impact on the phase composition and lattice parameters. In all cases the result was pure hexagonal hydroxyapatite without phase impurities. Figure 6 shows the SAED with identified planes for hydroxyapatite synthesized during the 1.5-minute reaction; in the remaining cases SAED was identical. No 


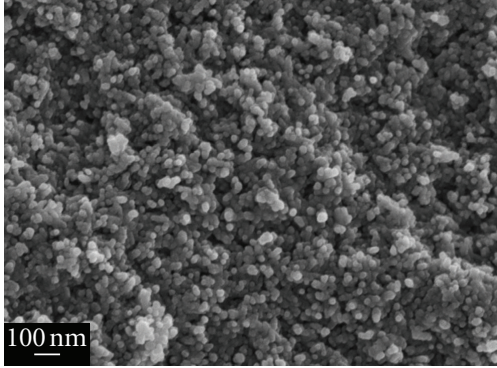

(a)

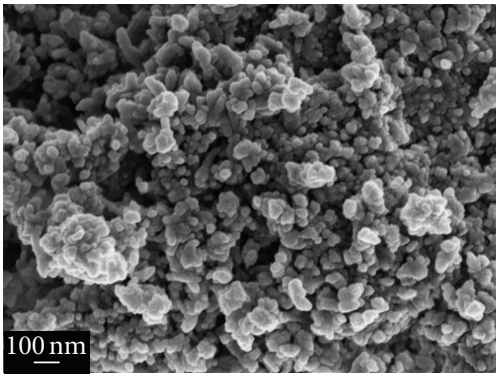

(c)

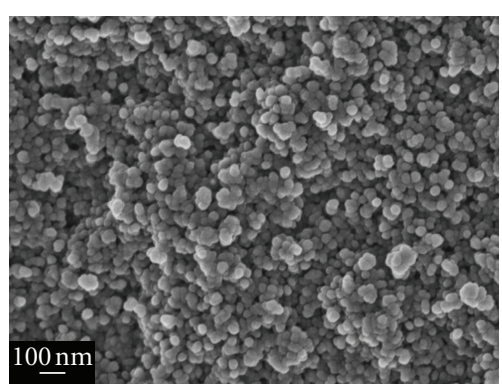

(b)

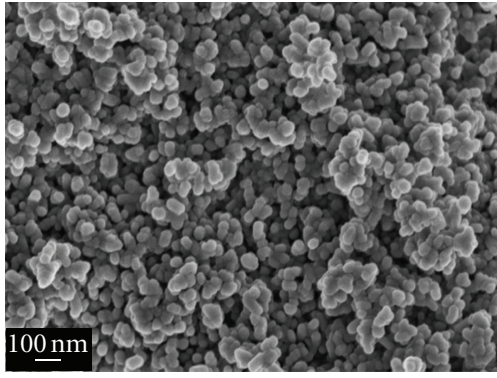

(d)

FIGURE 5: SEM micrographs of GoHAP synthesized in (a) 1.5-minute reaction, (b) 2.5-minute reaction, (c) 5.0-minute reaction, and (d) 10.0-minute reaction.

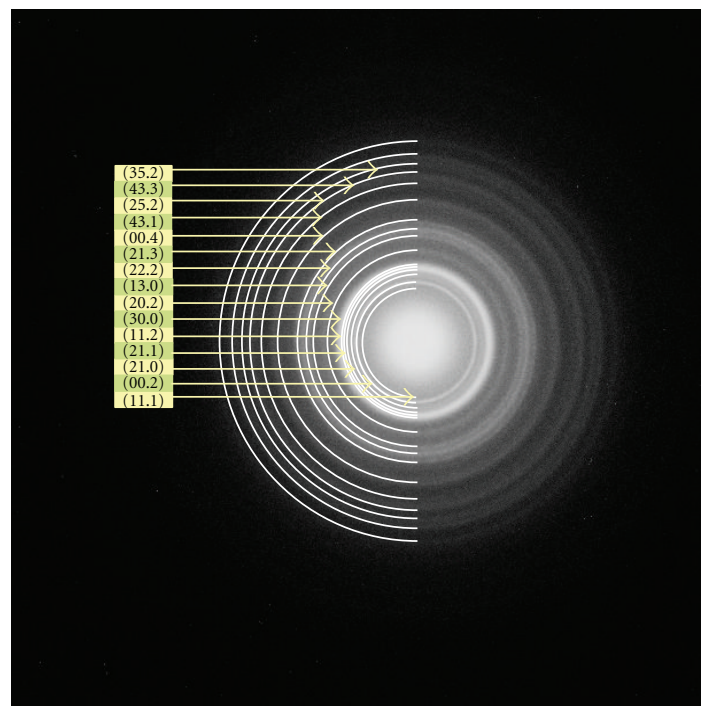

Figure 6: SAED with the identified planes.

other phases have been found in tested samples. The average grain size for GoHAP synthesized during the 1.5-minute reaction was $5.6 \mathrm{~nm}$ (Figure 7 ). After increasing the reaction time to 2.5 minutes, the average grain size barely changed; it was $5.8 \mathrm{~nm}$ but studies indicated that the particles were in the form of large, stable agglomerates. Further microwave heating caused an increase in the particle size and a decrease in the sample homogeneity. Figure 8 shows an image taken in the dark field of particles obtained from the 7.5-minute reaction, with a morphology ranging from spherical to almost needle-like shapes. The average grain size after the 7.5-minute reaction was $26.2 \mathrm{~nm}$. Reactions longer than 7.5 minutes increased the grain size to over $30 \mathrm{~nm}$.

A degradation test was conducted for GoHAP obtained during reactions with microwave radiation times of 1.5 , 2.5, 5.0, and 10.0 minutes. Commercially available HAp nanopowder, NanoXIM, was used as a reference material. The initial $\mathrm{pH}$ of the test solution was 7.47 , the conductivity was $6.82 \mathrm{mS} / \mathrm{cm}$, and the calcium ion concentration was $0.479 \mu \mathrm{mol} / \mathrm{dm}^{3}$. The results of the calcium ion concentration changes are shown in Figure 9. These results showed that in each day the GoHAP obtained from the shortest reaction (1.5 minutes) had the highest rate of degradation. Along with an increase in the microwave radiation time for the GoHAP synthesis there was decrease in the material solubility, until finally, in the case of GoHAP obtained from the longest (10 minutes) reaction, the achieved solubility value was close to the NanoXIM results. After 21 days of tests, the calcium ion concentration in the sample with NanoXIM remained nearly constant and achieved a value of $40.37 \mu \mathrm{m} / \mathrm{dm}^{3}$ by the end of test, which can be recalculated based on weight solubility to $4.0 \mathrm{mg} / \mathrm{dm}^{3}$. After three weeks of tests, the GoHAP obtained in 1.5 min reaction had twice as much solubility as NanoXIM, and, furthermore, in the fourth week there was an acceleration of solubility which led to a concentration of $199.6 \mu \mathrm{mol} / \mathrm{dm}^{3}$ calcium ions by the end of the test, equal to $20.0 \mathrm{mg} / \mathrm{dm}^{3}$. The GoHAP obtained with microwave radiation times longer than 1.5 minutes achieved solubility values in the range between the NanoXIM and GoHAP $1.5 \mathrm{~min}$ solubility, decreasing as a function of microwave radiation time. In the case of GoHAP obtained with the 2.5-minute reaction, the final 

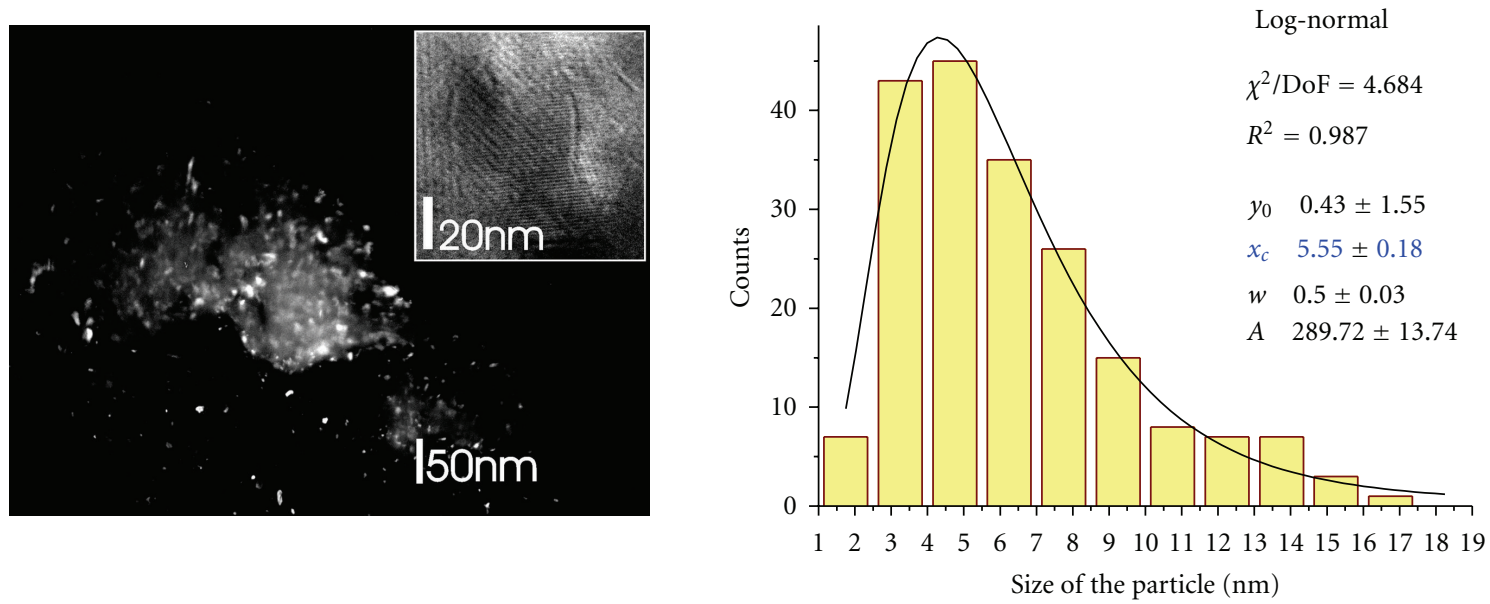

FIGURE 7: The dark field TEM image of GoHAP synthesized with a 1.5-minute reaction, and the histogram of the particle size distribution.
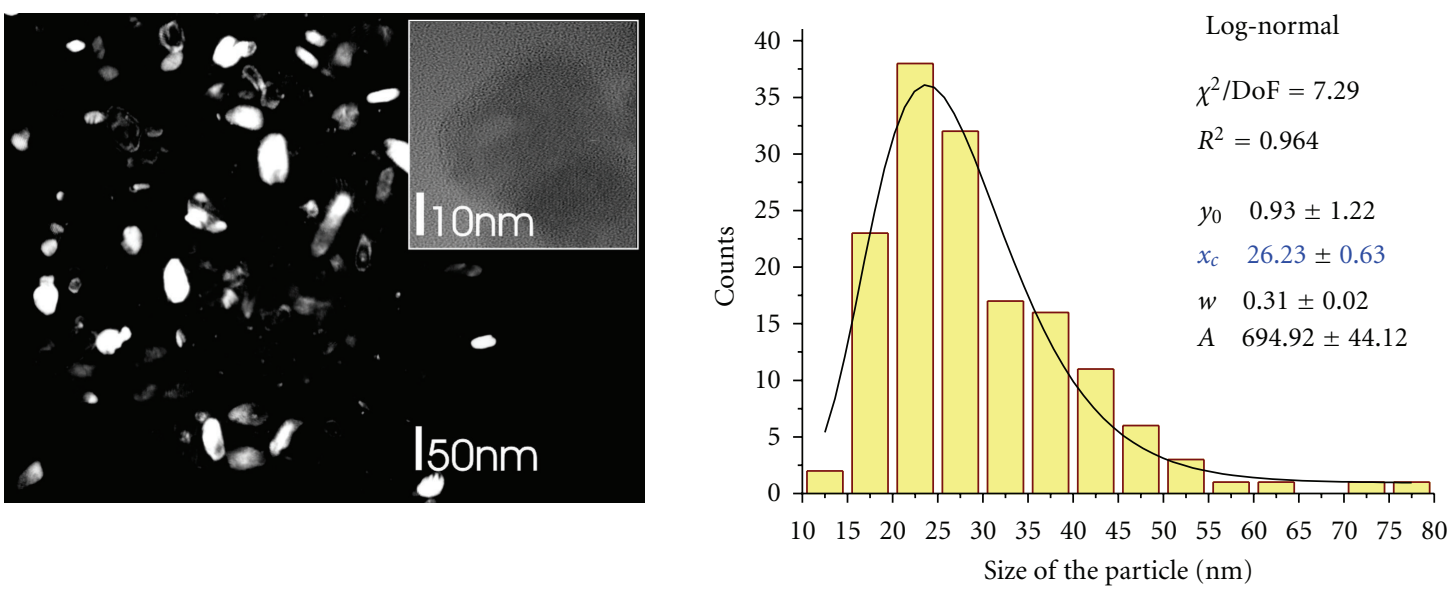

FIGURE 8: The dark field TEM image of GoHAP synthesized with a 7.5-minute reaction, and the histogram of the particle size distribution.

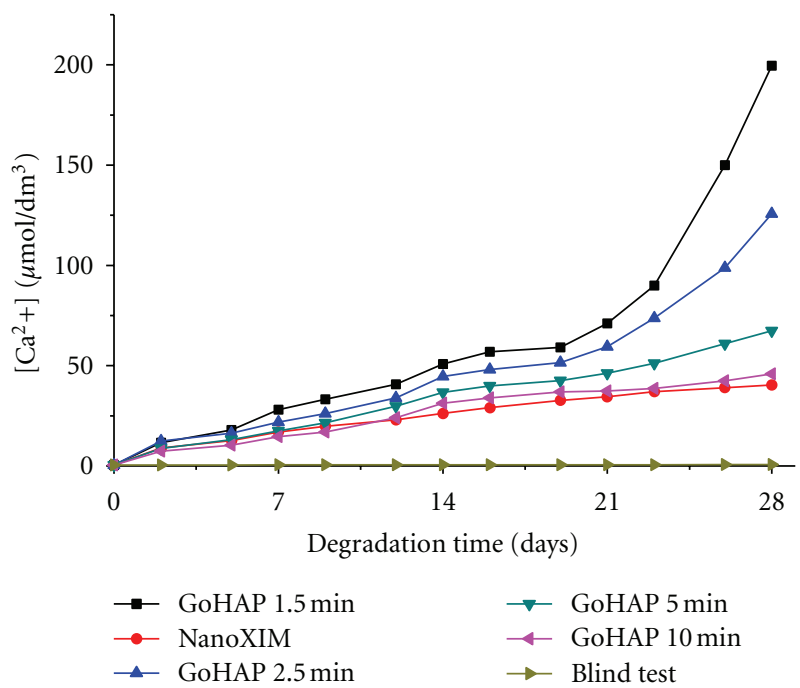

FIGURE 9: Calcium ion concentration changes for GoHAP synthesized with microwave radiation times of $1.5,2.5,5.0$, and 10.0 minutes, and for the commercial nanopowder, NanoXIM used as a reference material. calcium ion concentration was $125.7 \mu \mathrm{mol} / \mathrm{dm}^{3}$ which is equal to $12.6 \mathrm{mg} / \mathrm{dm}^{3}$ solubility. The GoHAP obtained with the 5 -minute reaction achieved $67.4 \mu \mathrm{mol} / \mathrm{dm}^{3}$ calcium ion concentration equal to $6.8 \mathrm{mg} / \mathrm{dm}^{3}$ solubility, and that from the longest (10 minutes) microwave reaction had $4.6 \mathrm{mg} / \mathrm{dm}^{3}$ solubility $\left(45.8 \mu \mathrm{mol} / \mathrm{dm}^{3}\right.$ calcium ion concentration).

The degradation test was additionally followed by determining the weight loss after 28 days of tests. During the test, NanoXIM lost $4 \%$ of its original weight, resulting in $7.0 \mathrm{mg} / \mathrm{dm}^{3}$ of solubility, and GoHAP obtained with 1.5minute reaction time lost over $22 \%$ of its initial weight, equal to $38.5 \mathrm{mg} / \mathrm{dm}^{3}$. GoHAP from the 2.5 -minute reaction had a solubility of $25.6 \mathrm{mg} / \mathrm{dm}^{3}$, from the 5 -minute reaction had solubility of $14.1 \mathrm{~g} / \mathrm{dm}^{3}$, and from the $10 \mathrm{~min}$ reaction had solubility of $8.7 \mathrm{mg} / \mathrm{dm}^{3}$, as determined from weight loss measurements. The solubility measured by the gravimetric method was in all cases approximately twice as large as the solubility measured by changes in the calcium ion concentration, probably due to nanopowder dispersion. The samples of GoHAP synthesized in $1.5 \mathrm{~min}$ reaction were deeply cracked on whole sample surface, but the test disk still was keeping its original shape, when the NanoXIM sample 
was cracked only in few places and was very weak. In case of the rest GoHAP samples, the density and depth of cracks were decreasing with powder reaction time increase-the GoHAP obtained in 10-minute reaction presented similar cracking to the NanoXIM disk, but it was much more stable during the mechanical operations, like disk transport, and so forth.

Such a high solubility rate should ensure a short degradation time of future scaffold. In degradation time longer than 28 days of conducted ISO test, GoHAP samples should keep or even accelerate their degradation rate, but in case of the real bone implants, the scaffolds degradation rate for time perspective longer than 28 days will depend on many other factors like new tissue formation process, and so forth, so that for long-time periods it should be checked by in vivo tests.

The degradation test showed that the developed method has the potential to adjust the material solubility according to the individual case needs in range from 4 to $20 \mathrm{mg} / \mathrm{dm}^{3}$, according to the ISO 10993-14 norm. The synthesis of this material with a programmable degradation rate was possible due to the implementation of a unique microwave heating technology (MSS) with very high energy density, which enables precise control of the material grain size growth. Compared to conventional heating, microwaves transmit energy directly to the entire volume almost without causing temperature gradients in the reaction vessel. The microwave radiation time may be regulated with $1 \mathrm{~s}$ precision, which enables precise grain size growth control.

The rapid microwave heating process leads to overheating of the reaction solution. From the overheated solution, a fine dispersion of nano-HAp precipitates starts to crystallise. Most likely, for short crystalisation times, kinetic processes dominate its growth, and nonstoichiometric crystallites grow with an nonequilibrium structure. Our experimental data show that this is the case for extremely short reaction times of 1.5 minutes. With increase of microwave radiation time the precipitates structure approaches the equilibrium one, and a fully stoichiometric structure is achieved for radiation times longer than 5 minutes (Figure 2). In consequence, precise microwave radiation time regulation allows to control hydroxyapatite stoichiometry and grain size growth. Furthermore the solution is rapidly cooled, so no secondary grain growth takes place $[29,39]$. As it was described in the introduction section a material solubility depend on material specific surface area-the material solubility increases with material grain size decrease [13] and its nonstoichiometry $[15,16]$. The decrease of $\mathrm{Ca} / \mathrm{P}$ molar ratio was increasing calcium ion concentration in tested solution due to increase of crystalline defects in the hydroxyapatite structure. The higher calcium deficiency is, the more defected crystalline structure will be, which is decreasing material stability and in consequence increases its solubility.

Precise grain size growth control which determines material specific surface area, together with material stoichiometry control both available via microwave radiation time regulation made the programming of hydroxyapatite solubility possible. The microwave solvothermal synthesis (MSS) with the high energy density allowed obtaining GoHAP powder with unique features which is a promising material for resorbable ceramic bone implants fabrication [40].

\section{Conclusions}

A fully crystalline hydroxyapatite nanopowder with programmed solubility rate was successfully synthesized by a novel MSS method using high-density microwave radiation as a heating mechanism. The material degradation rate was regulated by the amount of applied microwave radiation, which determined the particle size and stoichiometry of the obtained hydroxyapatite nanopowder and consequently enabled the material solubility to be programmed. The obtained nanopowder has unique properties. It is a pure crystalline, hexagonal hydroxyapatite nanopowder with a specific surface area ranging from 60 to almost $240 \mathrm{~m}^{2} / \mathrm{g}$ and a Ca/P molar ratio in the range of 1.57-1.67; these values are fully regulated by the applied microwave radiation time. The average particle size estimated by the TEM investigation was regulated between $6 \mathrm{~nm}$ to over $30 \mathrm{~nm}$. As the degradation study demonstrated, the developed method was able to control the material solubility in conditions simulating the human body in the range from $4 \mathrm{mg} / \mathrm{dm}^{3}$ - which is close to NanoXIM, a commercial HAp nanopowder-to $20 \mathrm{mg} / \mathrm{dm}^{3}$. The presented material has the potential to significantly improve the properties of ceramic bone scaffolds by allowing the implant degradation rate to be adjusted to individual situations.

\section{Acknowledgments}

This work was financed by the European Regional Development Fund within the Innovative Economy Operational Programme in the frame of the BIO-IMPLANT project "Bioimplants for the treatment of bone tissue lesions in oncological patients" (POIG.01.01.02-00-022/09) and by the SONOSCA ERANET-MATERA project as well as by the Institute of High Pressure Physics, PAS. The research subject was carried out with the use of equipment funded by the project CePT financed by the European Regional development Fund within the Operational Programme "Innovative Economy" for 2007-2013. The authors would like also to thank J. Mizeracki and A. Presz from the Institute of High Pressure Physics PAS, P. Dłużewski from the Institute of Physics PAS, and A. Karaś from the Institute of Electronic Materials Technology.

\section{References}

[1] J. R. Porter, T. T. Ruckh, and K. C. Popat, "Bone tissue engineering: a review in bone biomimetics and drug delivery startegies," Biotechnology Progress, vol. 25, no. 6, pp. 15391560, 2009.

[2] European Technology Platform Nanomedicine, Roadmap Report, 2009.

[3] C. F. Lord, M. C. Gebhardt, W. W. Tomford, and H. J. Mankin, "Infection in bone allografts. Incidence, nature, and treatment," Journal of Bone and Joint Surgery, vol. 70, no. 3, pp. 369-376, 1988. 
[4] B. H. Berrey, C. F. Lord, M. C. Gebhardt, and H. J. Mankin, "Fractures of allografts. Frequency, treatment, and endresults," Journal of Bone and Joint Surgery, vol. 72, no. 6, pp. 825-833, 1990.

[5] M. Aebi, "Introduction to update on osteochondral allograft surgery," in Bone Transplantation, M. Aebi and B. Regazzoni, Eds., Springer, Berlin, Germany, 1987.

[6] S. H. Li, J. R. De Wijn, P. Layrolle, and K. De Groot, "Synthesis of macroporous hydroxyapatite scaffolds for bone tissue engineering," Journal of Biomedical Materials Research, vol. 61, no. 1, pp. 109-120, 2002.

[7] B. Flautre, M. Descamps, C. Delecourt, M. C. Blary, and P. Hardouin, "Porous HA ceramic for bone replacement: role of the pores and interconnections-experimental study in the rabbit," Journal of Materials Science: Materials in Medicine, vol. 12, no. 8, pp. 679-682, 2001.

[8] S. S. Kim, M. Sun Park, O. Jeon, C. Yong Choi, and B. S. Kim, "Poly(lactide-co-glycolide)/hydroxyapatite composite scaffolds for bone tissue engineering," Biomaterials, vol. 27, no. 8, pp. 1399-1409, 2006.

[9] F. Barrère, C. A. van Blitterswijk, and K. de Groot, "Bone regeneration: molecular and cellular interactions with calcium phosphate ceramics," International Journal of Nanomedicine, vol. 1, no. 3, pp. 317-332, 2006.

[10] W. Suchanek and M. Yoshimura, "Processing and properties of hydroxyapatite-based biomaterials for use as hard tissue replacement implants," Journal of Materials Research, vol. 13, no. 1, pp. 94-117, 1998.

[11] R. Dingreville, J. Qu, and Mohammed Cherkaoui, "Surface free energy and its effect on the elastic behavior of nano-sized particles, wires and films," Journal of the Mechanics and Physics of Solids, vol. 53, no. 8, pp. 1827-1854, 2005.

[12] F. D. Fischer, T. Waitz, D. Vollath, and N. K. Simha, "On the role of surface energy and surface stress in phase-transforming nanoparticles," Progress in Materials Science, vol. 53, no. 3, pp. 481-527, 2008.

[13] G. Kaptay, "On the size and shape dependence of the solubility of nano-particles in solution," International Journal of Pharmaceutics, vol. 430, pp. 253-2257, 2012.

[14] T. J. Webster, R. W. Siegel, and R. Bizios, "Osteoblast adhesion on nanophase ceramics," Biomaterials, vol. 20, no. 13, pp. 1221-1227, 1999.

[15] M. P. Ginebra, E. Fernández, F. C. M. Driessens, and J. A. Planell, "Modeling of the hydrolysis of $\alpha$-tricalcium phosphate," Journal of the American Ceramic Society, vol. 82, no. 10 , pp. 2808-2812, 1999.

[16] J. L. Meyer and B. O. Fowler, "Lattice defects in nonstoichiometric calcium hydroxylapatites. A chemical approach," Inorganic Chemistry, vol. 21, no. 8, pp. 3029-3035, 1982.

[17] W. L. Suchanek, P. Shuk, K. Byrappa, R. E. Riman, K. S. TenHuisen, and V. F. Janas, "Mechanochemical-hydrothermal synthesis of carbonated apatite powders at room temperature," Biomaterials, vol. 23, no. 3, pp. 699-710, 2002.

[18] D. Choi and P. N. Kumta, "An alternative chemical route for the synthesis and thermal stability of chemically enriched hydroxyapatite," Journal of the American Ceramic Society, vol. 89, no. 2, pp. 444-449, 2006.

[19] S. J. Yan, Z. H. Zhou, F. Zhang, S. P. Yang, L. Z. Yang, and X. B. $\mathrm{Yu}$, "Effect of anionic PAMAM with amido groups starburst dendrimers on the crystallization of $\mathrm{Ca}_{10}\left(\mathrm{PO}_{4}\right)_{6}(\mathrm{OH})_{2}$ by hydrothermal method," Materials Chemistry and Physics, vol. 99, no. 1, pp. 164-169, 2006.
[20] A. Banerjee, A. Bandyopadhyay, and S. Bose, "Hydroxyapatite nanopowders: synthesis, densification and cell-materials interaction," Materials Science and Engineering C, vol. 27, no. 4, pp. 729-735, 2007.

[21] T. A. Kuriakosea, S. N. Kalkuraa, M. Palamichanyc et al., "Synthesis of stoichiometric nano crystalline hydroxyapatite by ethanol based sol-gel technique at low temperature," Journal of Crystal Growth, vol. 263, pp. 517-523, 2004.

[22] D. M. Liu, T. Troczynski, and W. J. Tseng, "Water-based sol-gel synthesis of hydroxyapatite: process development," Biomaterials, vol. 22, no. 13, pp. 1721-1730, 2001.

[23] K. Sonoda, T. Furuzono, D. Walsh, K. Sato, and J. Tanaka, "Influence of emulsion on crystal growth of hydroxyapatite," Solid State Ionics, vol. 151, no. 1-4, pp. 321-327, 2002.

[24] B. H. Chen, K. I. Chen, M. L. Ho, H. N. Chen, W. C. Chen, and C. K. Wang, "Synthesis of calcium phosphates and porous hydroxyapatite beads prepared by emulsion method," Materials Chemistry and Physics, vol. 113, no. 1, pp. 365-371, 2009.

[25] S. J. Kalita and S. Verma, "Nanocrystalline hydroxyapatite bioceramic using microwave radiation: synthesis and characterization," Materials Science and Engineering C, vol. 30, no. 2, pp. 295-303, 2010.

[26] D. Veljović, I. Zalite, E. Palcevskis, I. Smiciklas, R. Petrović, and D. Janaćković, "Microwave sintering of fine grained HAP and HAP/TCP bioceramics," Ceramics International, vol. 36, no. 2, pp. 595-603, 2010.

[27] S. Vijayan and H. Varma, "Microwave sintering of nanosized hydroxyapatite powder compacts," Materials Letters, vol. 56, no. 5, pp. 827-831, 2002.

[28] D. E. Clark and W. H. Sutton, "Microwave processing of materials," Annual Review of Materials Research, vol. 26, pp. 299-331, 1996.

[29] C. Leonelli and W. Lojkowski, "Main development directions in the application of microwave irradiation to the synthesis of nanopowders," Chimica Oggi, vol. 25, no. 3, pp. 34-38, 2007.

[30] Y. B. Khollam, A. S. Deshpande, A. J. Patil, H. S. Potdar, S. B. Deshpande, and S. K. Date, "Microwave-hydrothermal synthesis of equi-axed and submicron-sized $\mathrm{BaTiO}_{3}$ powders," Materials Chemistry and Physics, vol. 71, no. 3, pp. 304-308, 2001.

[31] H. Yang, C. Huang, X. Li, R. Shi, and K. Zhang, "Luminescent and photocatalytic properties of cadmium sulfide nanoparticles synthesized via microwave irradiation," Materials Chemistry and Physics, vol. 90, no. 1, pp. 155-158, 2005.

[32] A. Opalinska, C. Leonelli, W. Lojkowski et al., "Effect of pressure on synthesis of Pr-doped Zirconia powders produced by microwave-driven hydrothermal reaction," Journal of Nanomaterials, vol. 2006, Article ID 98769, 8 pages, 2006.

[33] Patent application P-369906, The method of nanoplates obtaining from synthetic hydroxyapatite and method of nanopowder with nanoplates obtaining from synthetic hydroxyapatite.

[34] T. Wejrzanowski, R. Pielaszek, A. Opalińska, H. Matysiak, W. Łojkowski, and K. J. Kurzydłowski, "Quantitative methods for nanopowders characterization," Applied Surface Science, vol. 253, no. 1, pp. 204-208, 2006.

[35] L. A. Solovyov, "Full-profile refinement by derivative difference minimization," Journal of Applied Crystallography, vol. 37, no. 5, pp. 743-749, 2004.

[36] P. W. Brown and B. Constantz, Hydroxyaptite and Related Materials, CRC Press, 1994. 
[37] J. Chang and E. Johnson, "Surface and bulk melting of small metal clusters," Philosophical Magazine, vol. 85, no. 30, pp. 3617-3627, 2005.

[38] K. Sudarsanan and R. A. Young, "Significant precisions in crystal structural details. Holly springs hydroxyapatite," Acta Crystallographica Section B, vol. 25, pp. 1534-1543, 1969.

[39] L. Perreux and A. Loupy, "A tentative rationalization of microwave effects in organic synthesis according to the reaction medium, and mechanistic considerations," Tetrahedron, vol. 57, no. 45, pp. 9199-9223, 2001.

[40] Patent application P-399701, The method of bone implants fabrication and the bone implant. 

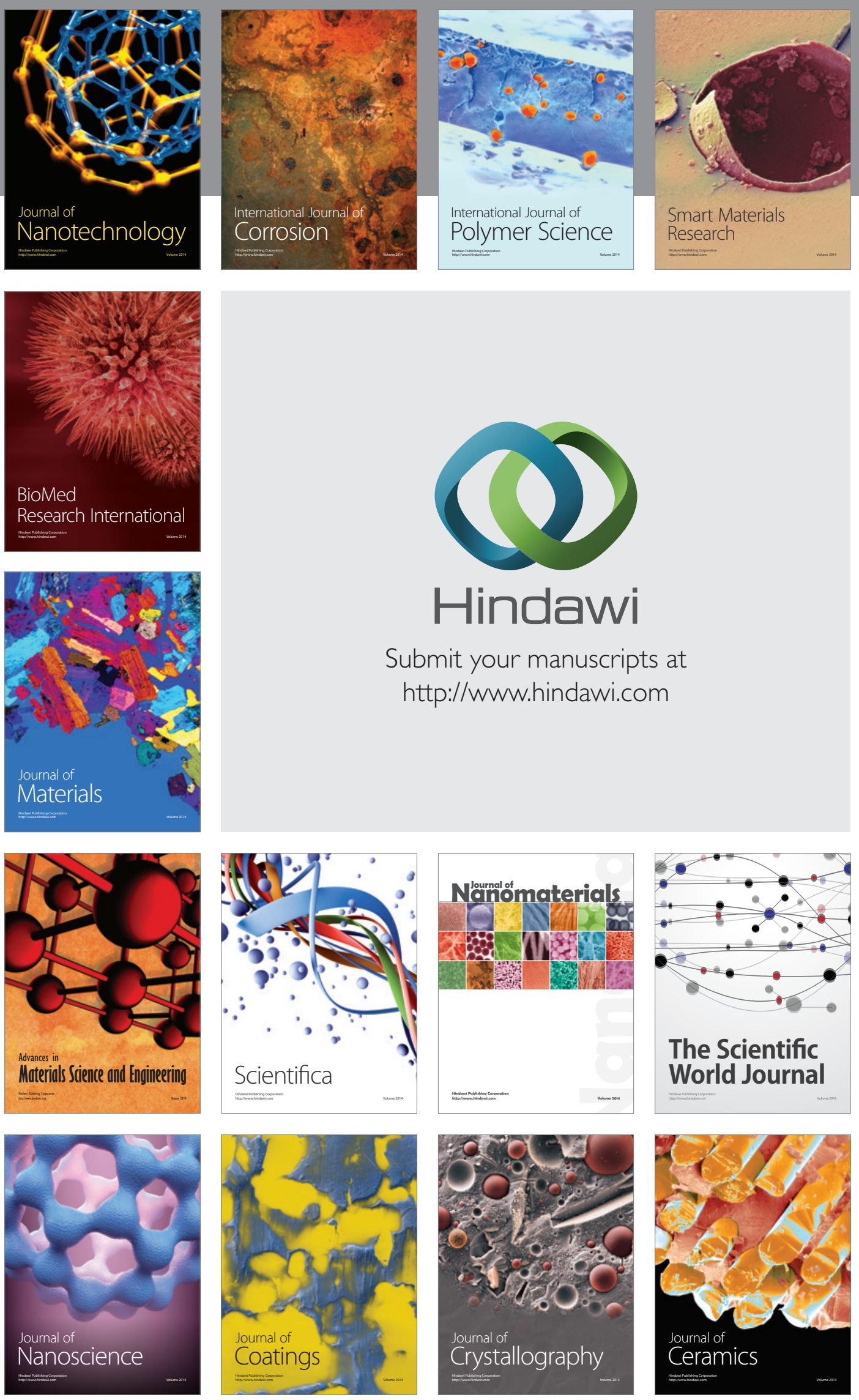

The Scientific World Journal

Submit your manuscripts at

http://www.hindawi.com

\section{World Journal}

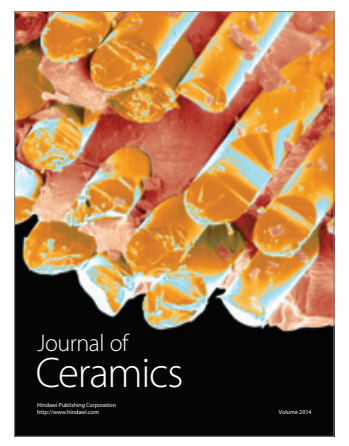

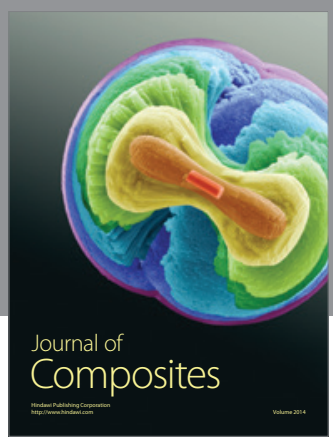
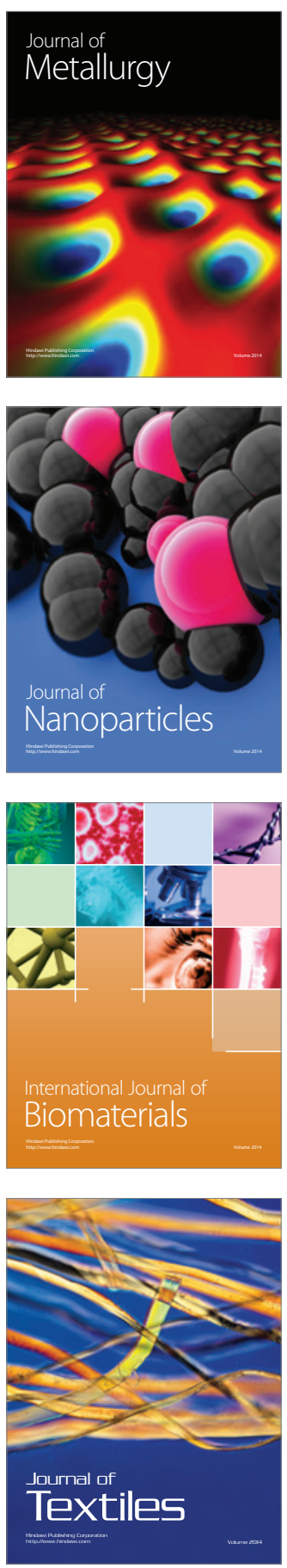